
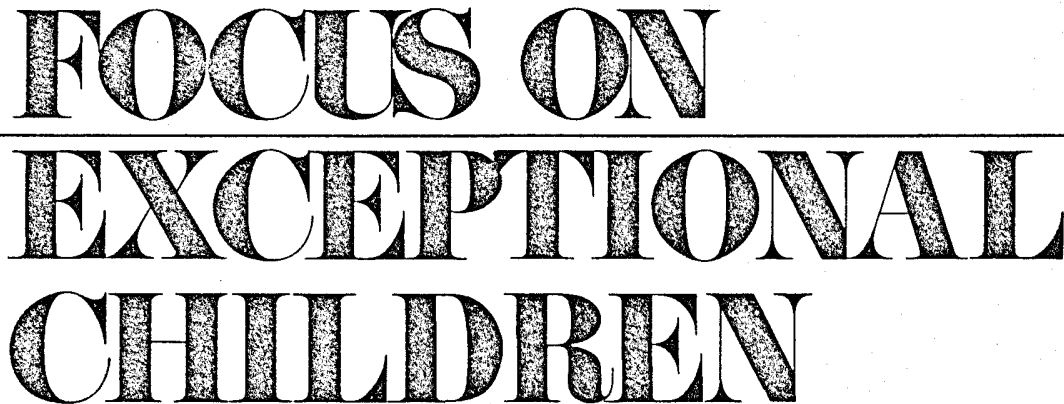

\title{
Microcomputers: A Course of Study for Gifted Students
}

\author{
Elinor Lipit Katz
}

Recently, Time magazine named the computer as "Man of the Year" for 1982, with the following rationale:

In 1982 a cascade of computers beeped and blipped their way into the American office, the American school and the American home. There are occasions ... . when the most significant force in a year's news is not a single individual but a process, and a widespread recognition that this process is changing the course of all other processes.

And futurist Isaac Asimov, when asked about the computer's impact on society, replied, "We are reaching the stage where problems that we must solve are going to become insolvable without computers. I do not fear computers. I fear the lack of them" (in Thomas, 1981, p. xiv).

Naisbitt (1982) suggested that we are shifting from an industrial society to an information society. The five most important factors related to this change are:

1. The information society is an economic reality, not an intellectual abstraction.

2. Innovations in communications and computer technology will accelerate the ... change by collapsing the time it takes to receive information.

3. New information technologies will be applied to old industrial tasks, then gradually applied to new activities, processes, and products.

4. This literacy-intensive society will need basic reading and writing skills.

5. The technology of the new information age is not absolute; it will succeed or fail according to the principle of high tech/high touch. (p. 19)

Dr. Katz is affiliated with the School of Education, University of Denver, where she is Director of the Bureau of Educational Services and Adjunct Assistant Professor of Special Education - Gifted Education. 
As in all segments of society, education is being impacted greatly by microcomputers, and this trend will continue into the future. Toffler (1980) has predicted the following educational changes: more learning will shift to outside rather than inside the classroom; the years of compulsory schooling will grow shorter; younger and older students will mingle in the learning environment and education will become more interspersed and interwoven with work.

By 1985 , an estimated $75 \%$ of all jobs will involve knowledge of computers. In a recent statement, the National Council of Teachers of Mathematics said, "Computer literacy is an essential outcome of contemporary education. Each student should acquire an understanding of the versatility and limitations of the computer through first-hand experience in a variety of fields" (Naisbitt, 1982).

Fortunately, students seem eager to learn to use computers. Mathieson (1982) has suggested that students like the microcomputer because it:

- gives them a sense of control.

- allows active learning.

- demands interaction.

- makes the user the decision maker.

- allows the user to stop and start in the learning task when ready and motivated.

- doesn't get angry.

- gives immediate feedback.

- provides risk-free simulations.

FOCUS ON EXCEPTIONAL CHILDREN (ISSN 0015-511X) (USPS 203-360) is published monthly except June, July, and August as a service to teachers, special educators, curriculum specialists, administrators, and those concerned with the special education of exceptional children. This journal is abstracted and indexed in Exceptional Child Education Resources, and is also available in microform from Xerox University Microfilms, Ann Arbor, Michigan. Subscription rates, $\$ 15.00$ per year. Copyright 1983, Love Publishing Company. All rights reserved. Reproduction in whole or part without written permission is prohibited. Printed in the United States of America. Second class postage is paid at Denver, Colorado. POSTMASTER: Send address changes to:

Love Publishing Company

Executive and Editorial Office

1777 South Bellaire Street

Denver, Colorado 80222

Telephone (303) 757-2579.

\section{EDITORIAL BOARD}

Edward L. Meyen

University of Kansas
Glenn A. Vergason Georgia State University
Richard J. Whelan

University of Kansas Medical Center
- provides a sense of mastery.

- is friendly, patient, and never gives detention.

All indications are that the students are ready, the microcomputers are ready, and the dynamics are in place for the microcomputer to become an integral part of the educational program. Many changes will take place in education as a result of the microcomputer.

\section{THE PROBLEM SOLVERS - GIFTED STUDENTS}

As noted, the microcomputer is heavily impacting on educational programs and technology. One of the unique features of this phenomenon is the rapid acquisition of computing skills by young gifted students. If given the opportunity and exposure to microcomputers, these students become computer literate in a brief time. Papert (1980), in Mindstorms, describes the microcomputer as the carrier of powerful ideas and the seeds of cultural change. He believes that computers will affect the way people learn and think, and that children should be taught to program the computer at a young age so that they can build their own learning environment.

The microcomputer can be used for mathematical concepts, of course, but it is equally useful for the acquisition of language arts skills. Noted educator of the gifted, Dorothy Sisk (1978), has discussed "Computers in the Classroom" as a new way for gifted students to express their ideas, allow for an in-depth learning experience, and assist with the acquisition of knowledge at a rapid pace.

Gifted students appear to have a natural affinity for microcomputers. Silverman (1982) reported that giftedness is most noticeable in manifestations of developmental advancement, language proficiency, unusual alertness and attentiveness, curiosity, and prolonged attention span. In addition, she included some of the characteristics of gifted students, a partial listing of which follows. They:

- have a unique, learning style.

- learn faster than most children.

- grasp relationships quickly.

- organize information in new ways.

- see many solutions to a problem.

- use abstract thought processes.

- delight in discovery and problem solving.

- enjoy working independently.

- persevere in areas of interest. (pp. 493-494)

Each of these traits helps explain why gifted students receive a great deal of challenge, excitement, and 
pleasure from programming the microcomputer. One of the greatest pleasures for a bright mind is to encounter a challenge. Doorly (1980) concurred that gifted students have the ability to think abstractly and to utilize the mental processes associated with higher levels of learning. She continued to say that the gifted see the microcomputer as mirroring the human mind and that by using logical sequencing, critical thinking, and mathematical concepts, these students design solutions to real problems. Gifted students are the problem solvers of the future, and the microcomputer is rapidly becoming essential in the problem-solving process.

\section{A MODEL FOR MICROCOMPUTER EDUCATION FOR GIFTED AND TALENTED STUDENTS}

The model for microcomputer education discussed in the following pages and depicted in Figure 1 has been designed for gifted and talented students. The scope of the model spans primary and secondary educational levels. Teachers are encouraged to use Levels 1 and 2 with all students, but Level 3 is most applicable for gifted students. The intent of this model is to teach students how to use a microcomputer to create their own learning experiences. Apple II Plus hardware and software were used to develop this model.

\section{Level 1: Computer Awareness}

The Minnesota Educational Computing Consortium (MECC) was awarded a grant by the National Science Foundation to explore the impact of pre-college educational programs designed to increase computer literacy. Results of this study, presented by Johnson, Anderson, Hanson, and Klassen (1982), were used to develop a comprehensive set of objectives to use in computer instruction. The following categories were developed:

$\begin{array}{ll}\text { Hardware } & \text { Applications } \\ \text { Programming and } & \text { Impact } \\ \quad \text { Algorithms } & \text { Attitudes, Values, } \\ \text { Software and Data } & \text { and Motivation } \\ \text { Processing } & \end{array}$

The authors suggest that these objectives (see Appen$\operatorname{dix} A$ ) would be useful in planning a computer awareness course of study. Most of the objectives have been incorporated into the Computer Awareness phase of this model.

\section{History of the Computer}

Most students are fascinated with the origins of the microcomputer. It is one of the few innovations that has had rapid growth during their own lifetime. Tatchell and Bennett (1982) traced the first electronic computers to World War II. These early computers were used to crack enemy codes and plot the flight path of shells. They used valves that frequently failed, and, therefore, a team of engineers was always needed to locate the "dud" valves in the huge machines.

\section{Level 1: Computer Awareness}

1. History of the Computer

2. How Computers Work

3. Computer Hardware and Software

4. Computers and Society

5. Computer Career Education

\section{Level 2: Computer Literacy}

1. Computer Terms

2. Applications of the Computer

3. Flow Charting Skills

4. Computer Languages

$\begin{array}{ll}\text { LOGO } & \text { Pascal } \\ \text { BASIC } & \text { Assembly }\end{array}$

5. Writing Programs

Level 3: Computer Programming

1. Writing Programs

2. Utilizing Peripheral Devices

3. Using Computers to Solve Problems

4. Advanced Programming Skills

5. Software Library 
After the war, interest did not resume until the 1950s, when transistors were invented. By the 1960s, the United States had entered the space race, and small, powerful computers were needed for the space crafts. The United States Government financed research that led to development of the "integrated circuit," commonly called the "chip." This breakthrough in the use of silicon chips led to creation of the microcomputer.

Another way of studying the history of computers is by "generations" of discoveries. By dividing the history of computers into four generations, we can see that each development involves reduction in size of hardware and, at the same time, an increase in power.

First ENIAC - a computer built in 1945, Generation: which weighed 30 tons and took up the space of a house. Its cost was over half a million dollars. One other drawback was that a valve would break every seven or eight minutes. (Tatchell \& Bennett, 1982)

Second Transistor - a device with three termiGeneration: nals. At the heart of a transistor is a tiny piece of pure silicon that does or does not conduct electricity. (Laurie, 1980)

Third Chip - electronic circuitry. The silicon Generation: base of the chip has miniscule switches and wires of thin films of metals. If photographed, the chip's terrain looks like streets, plazas, and buildings viewed from the air. (Boraiko, 1982)

Fourth Microprocessor - allowed for computer Generation: circuitry, which would have filled a room in 1945 , to fit on a $5 \mathrm{~mm}$-square silicon chip in 1971. (Boraiko, 1982)

By 1980 the chip, which is smaller than a contact lens, became the heart of today's microcomputer. It costs less than five dollars to produce and almost never breaks down.

\section{How Microcomputers Work}

Microcomputers are small, powerful, and multipurpose computers. They can work efficiently with numbers - adding, subtracting, multiplying, and dividing in a matter of seconds. Of equal importance is the word processing capability which allows students to write programs, keep records and diaries, and do their homework. Most microcomputers have graphics, sounds and music, and the capacity for playing many exciting games.
The key part of the microcomputer is the central processing unit (CPU), located inside the keyboard unit. It does all the work and has the memory. The CPU requires a set of instructions, called a program, to perform a command. Programs and data are input, and the results are called output. This can be represented as:

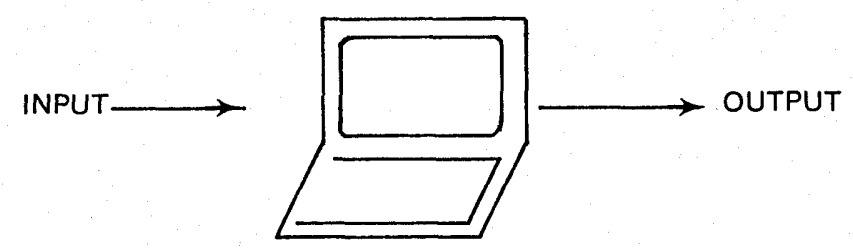

To communicate with computers, we have to translate numbers, letters, and symbols into a code of electrical pulses. The computer accepts a high-voltage electrical pulse as the digit 1; a low-voltage signal stands for 0 . This is called a binary system (it contains only two digits). Microcomputers digest information in chains of eight electrical pulses. These are called bytes. The CPU translates these commands into an instruction performed by the microcomputer.

\section{Computer Hardware and Software}

Microcomputers currently available offer many of the same features. The "intelligence" of the microcomputer is the CPU (the small silicon chip that allowed miniaturization of the microcomputer). Memory capabilities of microcomputers vary, but add-on memory units are available. A microcomputer uses three kinds of memory:

$$
\begin{aligned}
& \text { ROM - Read Only Memory } \\
& \text { RAM - Random Access Memory } \\
& \text { Mass Storage Memory }
\end{aligned}
$$

ROM is the permanent set of instructions built into the microcomputer. RAM is the active memory you program into the computer. The mass storage memory is a cassette or disk drive that gives the computer access to large amounts of data or programs.

A standard feature of all microcomputers is a keyboard. Most keyboards are arranged similar to those on typewriters, with the addition of some specialized keys. Some computer keyboards are easier to use than others. This comfort level affects the ease of programming.

Most computers have a VDU - visual display unit -either built into the system or as a separate monitor connected to the microcomputer. The VDU can be black 
and white, green (phosphorus), or a color monitor. Many microcomputers work efficiently with a small color television.

Peripheral is the term used for equipment added to the microcomputer. This can be a printer, game paddles (or joy sticks), or a modem for attaching the microcomputer to a telephone line, which allows access to data bases or information systems. In the near future, microcomputers will be attached to a videodisk player for interactive learning in the classroom.

The most important feature of a microcomputer is the availability of quality software (programs with accompanying documentation). Software is stored on tape cassettes or disks when not in use by the computer. The computer reads the software into its memory in order to use the programs (Thomas, 1981, p. 129). Advertisements, software directories, and computer magazines inform the public about the many types of software packages on the market. At present, software can be purchased to teach the basic skills and foreign languages, play games, create simulations, and monitor your stocks and bonds portfolio.

Many fine journals discuss the latest advances in computer education. One innovative publication has two subscription prices - one for the magazine and a delux rate for a disk of that month's computer programs. Students should be encouraged to read the monthly journals because of the rapidly changing technology in the microcomputer industry.

Software data bases are useful in providing information for students and teachers. MicroSIFT is a project of the Northwest Regional Educational Laboratory, in Portland, Oregon, which provides information about school-related software K-12. The Minnesota Educational Computing Consortium (MECC) coordinates and provides computer services to students, teachers, and administrators. Its Documentation Center makes available written materials from newsletters to curriculum guides. Non-Minnesota customers are asked to pay for the computer services.

To teach students how to evaluate software, first ask yourself the following questions; then train them to do the same:

1. Is documentation or good printed material available with the tape or disk?

2. Does the program run?

3. Is the program easy to use?

4. Is the activity educationally sound?

5. Who is in control - the user or the machine?

6. Does the program present the concept to be learned in a balanced way? (Naiman, 1982, pp. 35-36)

\section{Computers and Society}

Students should be made aware of the profound influence of computers in our lives, now and in the future. According to Cohen (1975) this change is likely to be resented or resisted at first. But, meanwhile, for those who accept them, home computers are becoming useful in keeping track of personal finances, doing income taxes, and recording addresses and telephone numbers. With the use of data bases we can print out sections of the daily newspaper, recall previous news articles, shop and bank by computer, and share electronic mail providing, of course, that the correspondent also has access to a computer.

Parker (1976) shocked us with his findings in Crime by Computer. "Computer abuse" is defined as any incident associated with computer technology in which a victim suffered a loss and the perpetrator made a gain. Errors and omissions are the most common cause of problems, but a secondary cause is the intentional tampering with computer programs, which could constitute embezzlement, other theft, or fraud.

Privacy and confidentiality are primary issues in today's society. Personal information has been collected and stored on millions of individuals in America. The credit rating system is one example of a personal data file. The issues that arise when computers enter this area of our lives are:

What information should be collected and stored? Should the individual be made aware of these data? Is privacy being violated?

Other controversial topics that could be addressed in classroom discussion include:

polling and politics.

computers and war simulations.

video games - are they bad for your health?

privacy rights.

ethics and computers.

\section{Computer Career Education}

Hodgkinson (1982) presented a list of the 10 most rapidly growing jobs, 1978-1980:

\section{Job}

Growth

Rate \%

Data Processing

Paralegal Personnel 
Computer Systems Analysts

Computer Operators

Office Machine Services

88

80

Computer Programmers

Aero-Astronautical Engineers

Fast Food Preparation Personnel

Employment Interviewers

Tax Preparers

For today's educators preparing students for their careers, an awareness that 5 of the 10 jobs above require direct knowledge of computers is an important consideration. To stretch a point, all of these positions may require some knowledge of the computer. For example, paralegal personnel will be assisted by word processing microcomputers, as well as a computer and modem for access to the legal library data base stored in Washington, DC.

The demand for skilled people will grow with the advances in computer technology. Here is a short list of possible career options:

Research (medicine, weather, energy, space)

Engineering (research and design)

Computer Programmers

Marketing Research (for business, industry, or education)

Technical Writers (for documentation)

Systems Engineering (use and installation)

Field Engineering (maintenance of systems)

Administration (planning and organizing)

Law (data bases in legal areas)

Education (teaching computer technology).

If your students are interested in a computer career, the following basic plan is suggested for exploring options:

1. Assess your skills (with the aid of existing assessment instruments).

2. Decide what careers are interesting to you.

3. Plan the education and training you will need to acquire those skills.

4. Take computer courses.

5. Explore a mentorship program (be placed with a person working in your career choice, for firsthand experience).

With the growth of computers, many new career opportunities will be available. Students today may have a career in robotics or the development of "artificial intelligence." As the technology advances, students should build their skills on the microcomputer. The key to future careers is computer literacy.

\section{Level 2: Computer Literacy}

A recent survey by the National Center for Educational Statistics (NCES) indicated that the number of microcomputers in education has tripled since 1980 . Computers were used by approximately 4.7 million students during the 1981-82 school year. At present, onefifth of the nation's elementary schools and three-fifths of all secondary schools have one or more microcomputers or computer terminals available for educational use. At the elementary level, microcomputers are used to teach computer literacy and basic skills. Junior high schools use microcomputers for teaching computer literacy and remedial work. More than half of the senior high schools use microcomputers to teach computer science, and computer literacy is the second most common use in high schools. (Kappan Newsnotes, Dec. 1982, p. 294)

The above study indicates that computer literacy is one of the primary goals at each educational level. Anderson and Klassen (1982) have proposed the following comprehensive definition of computer literacy as "whatever understanding, skills, and attitudes one needs to function effectively within a given social role that directly or indirectly involves computers" (p. 42). Luehrmann (1982) discussed computer literacy in terms of understanding the computer as a unique machine. If you add a computer to a typewriter, you have a word processor; or if you attach a computer to a moving mechanical device, it becomes a robot arm for industry. This remarkable machine can perform thousands of functions if given the proper instructions. To program the computer or to communicate with it, you must know one of the computer languages. Once you have these skills, you become computer literate. In many educational publications, computer literacy is referred to as the "fourth ' $r$ '."

Watt (1981) has divided computer literacy into four interrelated areas:

1. The ability to control and program a computer to achieve a variety of personal, academic, and professional goals.

2. The ability to use a variety of preprogrammed computer applications (software) for different purposes.

3. The ability to understand the growing impact of computers on our society. 
4. The ability to make use of ideas from the world of computer programming as part of an individual's collection of strategies for informational retrieval, communication, and problem solving.

\section{Computer Terms}

Computer technology and programming have introduced new terms that are necessary to function successfully in the microcomputer environment. The following list, extracted from Thomas (1981, pp. 119-131), focuses on the essential vocabulary for this model: algorithm

assembly

language

BASIC

binary system

bit

bug

byte

character

chip

command

compiler

computer

computer language
A step-by-step procedure; a flow chart.

A computer language that uses mnemonic names to stand for one or more machine language instructions, similar to shorthand.

Beginners All-purpose Symbolic Instruction Code - a high-level, commonly used computer language.

A number system based on the number 2 , represented by 1 and 0 ; each place in a number represents a power of 2.

The smallest unit of digital information.

An error in programming.

A basic unit of information in a computer.

A single item that can be arranged in groups to stand for information. The two forms are:

(1) graphic' symbols - numbers, letters

(2) binary digits - understood by computer.

A small piece of silicon on which thousands of electronic elements are implanted.

An instruction given to the system.

A program built into the computer that translates the high-level language-readable program for the computer.

A device that receives and then follows instructions to manipulate inmation.

A communication system usable with a computer.
CPU

Central Processing $U$ nit - the heart of the computer. It has three sections: arithmetic, control, and logic elements. cursor

data

disk

document

file

graphics

hardware

I/O

machine

language

microprocessor

peripheral

device

program

RAM

ROM

software
Movable indicator on the screen, or monitor.

Information given to or received from a computer.

A record-like, magnetic-coated piece of material that can store programs, data, or tables of information.

A written description of a piece of software or hardware.

Collection of related data.

The use of characters to form figures, or pictures.

Mechanical, magnetic, electrical, and electronic devices that make up a computer.

Input/Output of information in a computer system.

A programming language whose instructions are written in binary, octal, or hexadecimal notation.

An integrated circuit that can execute instructions.

A piece of equipment such as a printer or mass storage unit that interfaces with the computer but is not an integral part of the basic hardware.

A series of instructions to a computer that cause it to solve a problem or perform a task.

Random Access Memory - any memory that can be written on or read from by a program.

Read Only Memory - data or instructions programmed into the computer; cannot be reprogrammed.

Programs and accompanying documentation.

\section{Applications of the Computer}

With the increasing importance of the microcomputer in education, many applications will prove useful for students and teachers. Naiman (1982) has suggested four major instructional applications for the microcomputer: 
1. The computer as an object:
a. to be taught programming
b. to be taught problem solving
c. as a learning environment

2. The computer as a tool:
a. calculators and statistical packages
b. word processing
c. laboratory instrument
d. data base manipulation and searching
e. communications network
f. computer in the arts (graphics)

3. The computer as a teacher:
a. drill and practice
b. tutorial programs
c. curriculum-oriented games
d. simulations
e. logic and problem solving

4. The computer as a management aid:
a. students' schedules
b. students' academic records
c. students' attendance records
d. students' test scores

In addition to the above educational uses, Anderson and Klassen (1982, p. 48) have suggested the following computer applications in other areas:

medicine and health care
law enforcement and
criminal justice
education and training
engineering and design
business and banking
the office
transportation and
traffic control
defense systems

weather prediction

recreation government and politics the home the library manufacturing creative arts publishing public utilities

Knowledge of how computers are used in many segments of society can also promote future awareness of career opportunities in computer technology.

\section{Flow Charting Skills}

One of the important skills in computer programming is the development of algorithms, or flow charting skills. Students must be taught how to give correct output for simple algorithms. The flow chart should include some or all of the following elements: replacement

calculation

decision points

repetition (simple loops)

input and output operations.

Students can write algorithms in LOGO, BASIC, or Pascal. Figure 2 gives an example of an algorithm and program written by a gifted junior high student, with one month of experience in computer programming, using the Apple II Plus microcomputer.

\section{Computer Languages}

Computer languages facilitate communication between the programmer and the microcomputer. The machine language for the microcomputer is based on the binary system, which most individuals would have great difficulty in using for programming. Therefore, highlevel computer languages such as BASIC, LOGO, Pascal, FORTRAN, and COBOL have been developed to assist the programmer in programming (activating) the computer. In the model described here, the following computer languages are recommended for introduction of computer literacy in Level 2:

$$
\begin{aligned}
& \text { Beginning Language - LOGO } \\
& \text { Primary Language } \\
& \text { Intermediate Language - BASIC } \\
& \text { Advanced Language } \quad \text { - Assembly }
\end{aligned}
$$

More intensive training in computer languages takes place in Level 3. LOGO was developed as a simple but powerful language to use with very young students. It is excellent for older students too. Papert (1980) has described the LOGO environment as a computer language in which communication takes place with a "turtle." The turtle is an object to think with - a computer-controlled, cybernetic animal. The "turtle" moves around the screen by typing simple commands such as FORWARD 100, or RIGHT 90. The child's exploratory play leads to more sophisticated applications of programming. Simple geometric designs lead to more complex patterns. Creating graphics is an outstanding feature of LOGO. Even preschoolers are learning programming skills in a short time. In addition, LOGO is convenient for writing programs.

BASIC, the acronym for Beginners All-purpose $S y m-$ bolic Instruction Code, was developed at Dartmouth College in 1964 as a simple computer language for beginners. Almost all the microcomputers use some form of 
Flow Chart

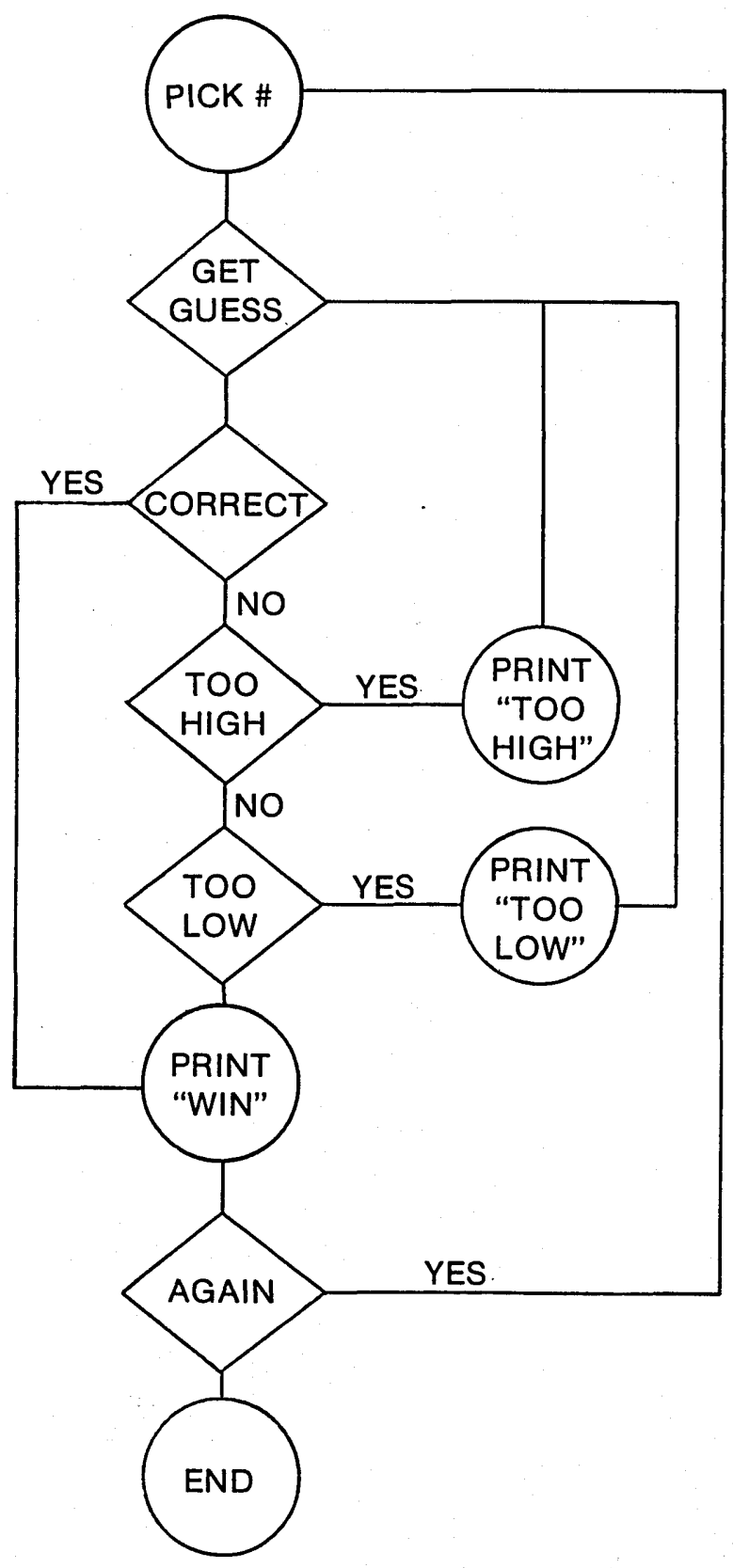

Computer Program

$10 X=$ INT $(100$ * RND (1)) +1

20 PRINT "GUESS MY NUMBER";

30 INPUT G

40 IF $\mathrm{G}=$ X THEN GOTO 70

50 IF G > X THEN PRINT "TOO HIGH": GOTO 20

60 IF G < X THEN PRINT "TOO LOW": GOTO 20

70 PRINT "YOU WIN!"

80 PRINT "AGAIN";

90 INPUT E \$

100 IF E $\$=$ "Y" Or E \$ = "YES" THEN GOTO 10

120 PRINT “BY”

130 END

\section{Computer Game: “Guess My Number”}

BASIC. Therefore computer students should have knowledge of this language. Papert (1980) has criticized BASIC, in the comparison that BASIC is to computation what QWERTY is to typing. BASIC has a small vocabulary and is easy to learn, but most programs in BASIC acquire "so labyrinthine a structure that only the most motivated and brilliant children learn to use it for more than trivial ends." Many gifted students adapt well to BASIC, but other computer languages would better serve their educational needs.

Pascal is rapidly becoming one of the more powerful computer languages for large programming and calculation tasks. Pascal is composed of English-like sentences arranged so that the finished program reads like a book. Pascal is a structured language that requires the programmer to define the nature, type, and range of 
items in an exacting way. The programmer must analyze the problem before creating a program to solve the problem. Fox and Waite (1981) have suggested Pascal as an ideal first language.

Assembly language is recommended for advancedlevel programmers. An advantage of learning this language is in its speed of execution of long programs. It is the shorthand of computer languages.

Pilot is an authoring language. It has a special set of commands that allow teachers and students to create individual lessons readily for all content areas.

\section{Writing Programs}

This is the gifted students' favorite time! The art of - writing computer programs can be successfully achieved only by having hands-on experiences at the microcomputer. In planning this aspect of the program, due consideration to time schedules is necessary to allow adequate time for programming. The following objectives, adapted from Anderson and Klassen (1982), can be used as a guideline for this part of the model:

1. Be able to identify the basic parts of the microcomputer.

a. Name the parts of the microcomputer.

b. Cite the difference between hardware and software.

c. Operate the CPU, monitor, and printer.

2. Be able to use a variety of software applications.

a. Be able to turn on the computer and load the program.

b. Be able to catalog, or list, programs.

c. Be able to modify a program for a specific need.

3. Understand the process of flow charting and programming.

a. Be able to follow and read a flow chart.

b. Be able to write a flow chart with at least two decisions.

c. Understand the terms data and program.

4. Be able to control and program a computer.

a. Be able to write a program (in LOGO, BASIC or Pascal) using the appropriate terminology.

b. Be able to enter the program into the computer, debug it, and save it for future use.

\section{Level 3: Computer Programming}

The long-a waited revolution in education may be here sooner than predicted, according to Bell (1981). The

\section{Knowledge}

1. Knowledge of Specfics

- knowledge of terminology

- knowledge of specific facts

2. Knowledge of Ways and Means of Dealing with Specifics

- knowledge of conventions

- knowledge of trends and sequences

- knowledge of classifications and categories

- knowledge of criteria

- knowledge of methodology

3. knowledge of principles and generalizations

- knowledge of theories and structures

\section{Comprehension}

1. Translation

2. Interpretation

3. Extrapolation

\section{Application}

1. Use Abstractions in Specific and Concrete Situations

\section{Analysis}

1. Analysis of Elements

2. Analysis of Relationships

3. Analysis of Organizational Principles

\section{Synthesis}

1. Production of a Unique Communication

2. Production of a Plan for Operation

3. Derivation of a Set of Abstract Relations

\section{Evaluation}

1. Judgments in Terms of Internal Evidence

2. Judgments in Terms of External Evidence

From B. S. Bloom, M. D. Engelhart, E. J. Furst, W. H. Hill, \& D. R. Krathwohl, Taxonomy of educational objectives, Handbook I: Cognitive domain. (New York: David McKay Co., 1956). 
The creative process applied to problem solving:

1. Fact-finding: gathering data in preparation for defining the problem

- Identify the problem by asking questions: Who? What? Where? When? Why?

2. Problem-finding: analyzing problematic areas in order to pick out and point up the problem to be attacked

- Question - "In what ways might I ...?"

- Gather data

3. Idea-finding: idea production - thinking up, processing, and developing numerous possible leads to solutions

- Put to other uses

- Adapt
- Modify

- Magnify

- Rearrange

- Combine

4. Solution-finding: evaluating potential solutions against defined criteria

- Establish criteria

- Evaluate

- Verify

- Test

5. Acceptance-finding: adoption - developing a plan of action and implementing the chosen solution

- Implement

- Prepare for acceptance

The following diagram suggests the way in which this process alternates within each step between "imaginative" (divergent) thinking and "judicial" (convergent) thinking.

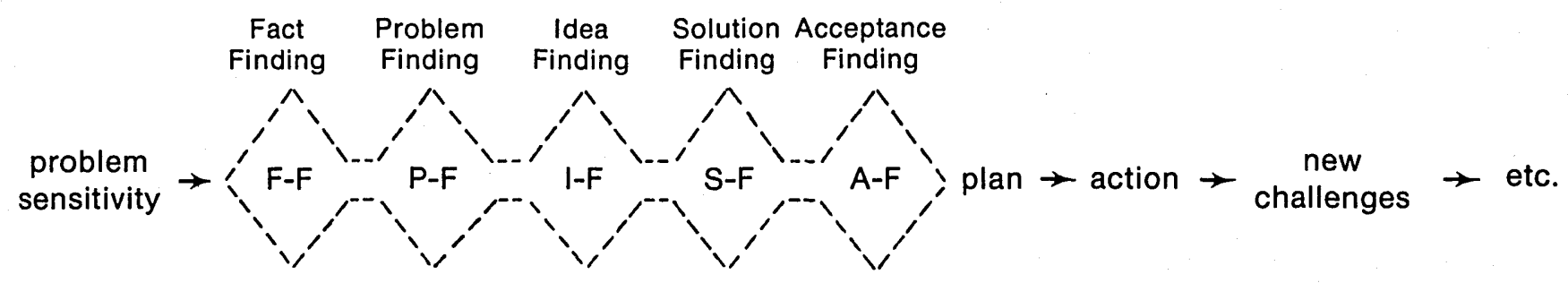

From S. J. Parnes, B. Noller, \& A. Biondi, Guide to creative action (New York: Charles Scribner \& Sons, 1977). Also, A. F. Osborn, Applied imagination (New York: Charles Scribner \& Sons, 1963).

FIGURE 4

Creative Problem Solving

classroom computer can teach students to analyze, evaluate, and develop complex skills. Two of the basic tenets of gifted education are represented in Bloom's Taxonomy and in the Problem Solving Model (see Figures 3 and 4). The skills of analysis and synthesis are essential components of computer programming. Gifted students can learn to write a program to tutor others, play a game, simulate a situation, or solve an exercise by analyzing the topic and synthesizing it into a logical program. In writing a program, the student utilizes the six steps in the problem-solving method. Teaching gifted students to program the computer improves both their cognitive and affective skills.

\section{Writing Programs}

Most gifted students are highly motivated to develop computer programming skills. This process takes a great deal of time at the microcomputer. The ability to write a simple program was introduced in Level 2. At Level 3, the intention is for gifted students to gain mastery of the 
computer language (LOGO, BASIC, or Pascal). This is a learning-by-doing activity time.

Another key component of this segment of the model is for the student to learn subject matter such as mathematics, science, social studies, language arts, English, and foreign language skills on the microcomputer. This can be accomplished in two ways. First, the student can use educational software written for the content area. Many fine commercial programs are available through computer companies or educational computer consortiums. Second, students can use their computer programming skills to develop educational games, simulations, or activities in specific content areas. Rowney (1982) has discussed how word processing, statistical analysis, and data management computer activities assist him in his historical research.

Students who have ready access to a microcomputer will use their skills for writing programs, and in time will do homework assignments on the microcomputer. One innovative school, Cherry Creek High School, in the Denver metropolitan area, has a microcomputer laboratory for computer science classes, and in addition has several other microcomputers in the science laboratories. This allows students to work out problems related to physics, biology, or chemistry in the laboratory when they are working on a scientific experiment.

\section{Utilizing Peripheral Devices}

Many varieties of peripherals are available to enhance the microcomputer's capabilities. The following peripherals are suggested for educational purposes:

1. Printer. A printer allows students to have a written copy of their computer work. One printer can be used with any number of microcomputers. Students using word processing for their school subjects will make good use of the printer.

2. Modem. The modem is a device attached to the telephone, which enables a computer to send and receive signals to and from another computer. Its primary advantage is the access to data bases and large memory/storage systems. The data base systems are the electronic libraries of today.

3. Language Cards or Disks. As suggested in Level 2, the computer languages of LOGO, BASIC, Pascal, and Pilot are recommended for this model. Each computer language, except BASIC, has to be purchased as additional software for the microcomputer.
4. Video Disk. In the near future, the video disk will become a common peripheral for the microcomputer. This educational tool can be used for interactive learning, as well as for information storage and retrieval. The video disk can store words, numbers, pictures, and movies. Students can view the program and stop at a single frame to view an actual photograph or computer graphics.

\section{Using Computers to Solve Problems}

In the beginning stages of computer programming, students write simple programs that may calculate the area of a house for new carpeting; draw a graphic design such as a pyramid which appears on the screen in sequence; or create a word quiz for other students.

As the gifted student develops a level of mastery with the microcomputer, the programs become longer and more complex, and the student can move into the realm of problem-solving strategies. Structured programming techniques are most helpful at this phase of development. Barstow (in Nazarro, 1981) gives several examples of gifted and talented students utilizing the computer for problem solving in their science research projects. For example:

Lisa, a high school student, used the computer to study the correlation between crime and weather. She based her study on crime statistics from police and compared it to weather data for a five-year period. Results: [Of the weather variables] temperature had greatest influence on crime.

$$
* * *
$$

Andy, Steve, and John, all age 14 , are creating a computer game similar to Dungeons and Dragons. They have designed a unique set of characters and challenging experiences for the young at heart. When it is completed, they plan to package and market their software.

Computer programming skills tie in well with the problem-solving process. Students who are competent in these skills will provide much of the scientific and technological information of the future.

\section{Advanced Programming Skills}

Gifted students will continue to develop programming skills in LOGO or Pascal. But for some of the skillful computer programmers, the high-level computer languages will prove too slow for long, complex programs. A short-cut is to learn the Assembly language, which translates mnemonic, alphabet codes into machinelanguage instructions. Assembly language can be a powerful and efficient tool that uses the least memory 
-an important factor in certain applications. Disadvantages are that Assembly language is tricky to use, it is often lengthy, and errors are difficult to find. After analyzing the pros and cons of Assembly language, a programmer should make the decision to pursue it or not according to his or her needs.

\section{Software Library}

A library is usually associated with books, but in this model a library of software is highly recommended. Disks and tapes may be purchased commercially at the beginning. In time, students' work should become an integral part of the software library. Computer programs can be created and shared for mutual learning experiences. The software library is the finest product of a comprehensive computer program.

\section{CONCLUDING REMARKS}

Educators are aware of the growing impact of microcomputers on education. The model presented here provides a methodology for developing computer competency a mong gifted and talented students. A survey of the "Computer in Education" research by Bracy (1982) divides the results into three categories: achievement, affective/motivational, and social. In the category of achievement, the survey revealed that instruction with computers improved retention and speed of learning. In the affective/ motivational category, students consistently reported that they enjoyed the ability to work at their own pace and the lack of embarrassment about their mistakes. In addition, students felt more in control of things using the computer. Findings in the category of social outcomes indicate that the computer fosters a cooperative problem-solving attitude among students. This research supports the use of microcomputers in the learning environment. In conclusion, Papert (1981) has stated:

A very important feature of work with computers is that the teacher and learner can be engaged in a real intellectual collaboration....

\section{APPENDIX A: \\ COMPUTER LITERACY OBJECTIVES}

(adapted from Johnson, Anderson, Hansen, \& Klassen, 1982)

Computer Literacy Objectives - Cognitive

Hardware $(\mathbf{H})^{\mathbf{a}}$

*H.1.1 Identify the five major components of a computer: input equipment, memory unit, control unit, arithmetic unit, output equipment.
${ }^{*}$ H.1.2 Identify the basic operation of a computer system: input of data or information, processing of data or information, output of data or information.

*H.1.3 Distinguish between hardware and software.

*H.1.4 Identify how a person can access a computer: for example,

1. via a keyboard terminal.

a. at site of computer.

b. at any distance via telephone lines.

2. via punched or marked cards.

3. via other magnetic media (tape, diskette).

*H.1.5 Recognize the rapid growth of computer hardware since the 1940 s.

*H.2.1 Determine that the basic components function as an inter-connected system under the control of a stored program developed by a person.

*H.2.2 Compare computer processing and storage capabilities to the human brain, listing some general similarities and differences.

Programming and Algorithms (P)

Note: The student should be able to accomplish objectives $1.2-2.5$ when the algorithm is expressed as a set of English language instructions and is in the form of a computer program.

P.1. Recognize the definition of "algorithm."

"P.1.2 Follow and give the correct output for a simple algorithm.

*P.1.3 Given a simple algorithm, explain what it accomplishes (i.e., interpret and generalize).

*P.2.1 Modify a simple algorithm to accomplish a new, but related, task.

P.2.2 Detect logic errors in an algorithm.

P.2.3 Correct errors in an improperly functioning algorithm.

P.2.4 Develop an algorithm for solving a specific problem.

P.2.5 Develop an algorithm that can be used to solve a set of similar problems.

Software and Data Processing (S)

S.1.1 Identify the fact that we communicate with computers through a binary code.

S.1.2 Identify the need for data to be organized if it is to be useful.

S.1.3 Identify the fact that information is data that has been given meaning.

S.1.4 Identify the fact that data is a coded mechanism for communication.

S.1.5 Identify the fact that communication is the trans mission of information via coded messages.

* Denotes core objectives.

a. Note that the coding is $\mathrm{H}-$ Hardware, $\mathrm{P}-$ Programming and Algorithms, S - Software and Data Processing, A - Applications, I - Impact. Also, for each statement the first digit after the letter refers to a cognitive level -1 indicating a low-level, generally a skill or knowledge of facts, and 2 standing for a higher level of understanding, requiring some analysis and/or synthesis. The final digit is merely a count of items within each level. Whereas no priority is intended with the final digit, there has been an attempt to place the ideas in some sort of logical sequence. 
*S.1.6 Identify the fact that data processing involves the transformation of data by means of a set of predefined rules.

*S.1.7 Recognize that a computer needs instructions to operate.

*S.1.8 Recognize that a computer gets instructions from a program written in a programming language.

*S.1.9 Recognize that a computer is capable of storing a program and data.

*S.1.10 Recognize that computers process data by searching, sorting, deleting, updating, summarizing, moving, and so on.

*S.2.1 Select an appropriate attribute for ordering of data for a particular task.

*S.2.2 Design an elementary data structure for a given application (that is, provide order for the data).

*S.2.3 Design an elementary coding system for a given application.

Applications (A)

*A.1.1 Recognize specific uses of computers in some of the following fields:

a. medicine.

b. law enforcement.

c. education.

d. engineering.

e. business.

f. transportation.

g. military defense systems.

h. weather prediction.

i. recreation.

j. government.

k. the library.

1. creative arts.

A.1.2 Identify the fact that many programming languages are suitable for a particular application for business or science.

*A.1.3 Recognize that the following activities are among the major types of applications of the computer:

a. information storage and retrieval.

b. simulation and modeling.

c. process control - decision making.

d. computation.

e. data processing.

*A.1.4 Recognize that computers are generally good at information-processing tasks that benefit from:

a. speed.

b. accuracy.

c. repetition.

*A.1.5 Recognize that some limiting considerations for using computers are:

a. cost.

b. software availability.

c. storage capacity.

*A.1.6 Recognize the basic features of a computerized information system.

*A.2.1 Determine how computers can assist the consumer.

*A.2.2 Determine how computers can assist in a decisionmaking process.

*A.2.3 Assess the feasibility of potential applications.

*A.2.4 Develop a new application. a. keypuncher/keyoperator.

b. ' computer operator.

c. computer programmer.

d. systems analyst.

e. computer scientist.

*I.1.2 Recognize that computers are used to commit a wide variety of serious crimes, especially stealing money and stealing information.

*I.1.3 Recognize that identification codes (numbers) and passwords are a primary means for restricting the use of computer systems, computer programs, and data files.

I.1.4 Recognize that procedures for detecting computerbased crimes are not well developed.

*I.1.5 Identify some advantages or disadvantages of a data base containing personal information on a large number of people (e.g., the list might include value for research and potential for privacy invasion).

I.1.6 Recognize several regulatory procedures; for example, privilege to review one's own file and restrictions on the use of universal personal identifiers that help to ensure the integrity of personal data files.

*I.1.7 Recognize that most "privacy problems" are characteristic of large information files whether or not they are computerized.

*I.1.8 Recognize that computerization both increases and decreases employment.

*I.1.9 Recognize that computerization both personalizes and impersonalizes procedures in fields such as education.

*I.1.10 Recognize that computerization can lead to both greater independence and dependence on one's tools.

*I.1.11 Recognize that, whereas computers do not have the mental capacity that humans do, computers have been able, through techniques such as artificial intelligence, to modify their own instruction set and do many of the information-processing tasks that humans do.

"I.1.12 Recognize that alleged "computer mistakes." are usually mistakes made by people.

* I.2.1 Plan a strategy for tracing and correcting a computer-related error, such as a billing error.

1.2.2 Explain how computers make public surveillance more feasible.

*I.2.3 Recognize that even though a person does not go near a computer, he or she is affected indirectly because society has changed in many sectors as a consequence of computerization.

1.2.4 Explain how computers can be used to effect the distribution and use of economic and political power.

Computer Literacy Objectives - Affective

(Attitude, Values, and Motivation) $(\mathrm{V})^{\mathrm{b}}$

*V.1 Does not feel fear, anxiety, or intimidation from computer experiences.

*V.2 Feels confident about his or her ability to use and control computers.

*V.3 Values efficient information processing provided that it does not neglect accuracy, the protection of individual rights, and social needs. 
*V.4 Values computerization of routine tasks as long as it frees people to engage in other activities and is not done as an end in itself.

*V.5 Values increased communication and availability of information made possible through computer use, provided that it does not violate personal rights to privacy and accuracy of personal data.

V.6 Values economic benefits of computerization for a society.

V.7 Enjoys and desires work or play with computers, especially computer-assisted learning.

V.8 Describes past experiences with computers with positive-affect words such as "fun," "exciting," "challenging," and so on.

V.9 Given an opportunity, spends some free time using computer.

\section{Summary}

The lists of objectives above could use further description. In particular, note that A.2.1 and A.2.2 speak to the notion of assisting the consumer or in decision making. In their phrasing, these objectives tend to suggest the positive aspects of computing. Of course, they must also include aspects involving limitations of the machine - in particular the aspects of decision making that relate to ethical and moral considerations.

Whereas the objectives are intended to provide a broad perspective, one area has been omitted - the details of early history (e.g., Babbage and Hollerith). This was a conscious decision based on discussions among the investigators and input from the review panel and other knowledgeable persons. This is not to suggest that the topic is not interesting or motivating but, rather, that it reflects the bias that such knowledge is not really functional or prerequisite to an understanding of the other areas.

The lists of objectives are quite extensive, but complete coverage is not feasible within any single course, and even less feasible as an addition to the school mathematics curriculum. If we view computer literacy in this broad sense, however, you "pick and choose," if you will, and allocate selected activities/experiences to supplant various areas in the total school curriculum, including mathematics. Another option is to allocate a portion of some year to a course called "Computer Awareness" or "Computer Literacy" and to select the objectives that require some reasonable time for study. These decisions should be made by those most suited for the task - the teachers in the school.

These lists of objectives should provide a basis for making decisions about computer uses in gifted education, but the objectives by no means do all your computer-related work for you. In particular, the language used in many of the objectives will probably have to be rephrased if it is to be communicated effectively to younger students. Also, the objectives should be translated into a form appropriate for assessment. The research project has developed items for the statements designated as core and will disseminate information about the tests in the near future. Of course, the assessment is most appropriate for determining the effectiveness of a given computer literacy curriculum and, at present, this is a relatively undeveloped area.

\section{REFERENCES}

Anderson, R. E., \& Klassen, D. L. A conceptual framework for developing computer literacy. In Center for Learning Technologies, Computer literacy: An introduction. Albany, NY: State Education Department, 1982, pp. 41-52.

Bell, F. Classroom computers: Beyond the 3 R's. In Nazarro, J. N. (Ed.), Computer connections: For gifted children and youth. Reston, VA: Council for Exceptional Children, 1981, pp. 9-11.

Boraiko, A. A. The chip: Electronic mini-marvel. National Geographic, 1982, 162(4), 421-458.

Bracy, G. W. Computers in education: What the research shows. Electronic Learning, 1982, 2(3), 51-55.

Cohen, D. The human side of the computer. New York: McGraw-Hill, 1975.

Doorly, A. Microcomputers for gifted microtots. $G / C / T, 1980,14$, 62-64.

Fox, D., \& Waite, M. Pascal primer. Indianapolis, IN: Howard W. Sams \& Co., 1981.

Hodgkinson, H. What is still right with education. Phi Delta Kappan, 1982, 64(4), 231-236.

Johnson, D. C., Anderson, R. E., Hansen, T. P., \& Klassen, D. L. Computer literacy - What is it? In Center for Learning Technologies, Computer literacy: An introduction. Albany, NY: State Department of Education, 1982, pp. 30-35.

Kappan Newsnotes, 1982, 64(4), 294.

Laurie, P. The micro revolution. New York: Universe Books, 1980.

Luehrmann, A. Computer literacy - What should it be? In Center for Learning Technologies, Computer literacy: An introduction. Albany, NY: State Department of Education, 1982, pp. 36-40.

Mathieson, D. A. Computers: From confusion to collaboration. Educational Leadership, 1982, 40(2), 13-16.

Naiman, A. Microcomputers in education: An introduction. Cambridge, MA: Technical Education Research Centers, 1982.

Naisbitt, J. Megatrends. New York: Warner Books, 1982.

Nazarro, J. (Ed.). Computer connections: For gifted children and youth. Reston, VA: Council for Exceptional Children, 1981.

Papert, S. Mindstorms: Children, computers, and powerful ideas. New York: Basic Books, 1980.

Papert, S. Computers and computer cultures. In Nazarro, J. N. Computer connections: For gifted children and youth. Reston, VA: Council for Exceptional Children, 1981, pp. 3-11.

Parker, D. B. Crime by computers. New York: Charles Scribner's Sons, 1976.

Rowney, D. K. The historian and the microcomputer. Byte, 1982, $7(7), 166-176$.

Silverman, L. Giftedness. In E. L. Meyen (Ed.), Exceptional children in today's schools. Denver, CO: Love Publishing Co., 1982.

Sisk, D. Computers in the classroom. G/C/T, 1978, $l(1), 18-21$.

Tatchell, J., \& Bennett, D. In L. Watts, L. (Ed.), Guide to understanding the micro: How it works and what it can do. London: Osborne Publishing Ltd., 1982.

Thomas, J. L. (Ed.). Microcomputers in the schools. Phoenix, AZ: Oryx Press, 1981.

Toffler, A. The third wave. New York: William Morrow \& Co., 1980.

Watt, D. H. Computer literacy: What schools should be doing about it. In Thomas, J. L. (Ed.). Microcomputers in the schools. Phoenix, AZ: Oryx Press, 1981.

Watt, D. LOGO in the schools. Byte, 1982, 7(8), 116-137.

\section{ADDITIONAL REFERENCES}

Abelson, H. A beginner's guide to LOGO. Byte, 1982, 7(8), 88-115. Ahl, D. What's wrong with the little red schoolhouse? Best of Creative Computing, 1, pp. 6-7. 
Alcock, D. Illustrating BASIC. Cambridge, England: Cambridge University Press, 1977.

Bejar, I. I. Videodiscs in education; integrating the computer and communication technologies. Bvte, 1982, 7(16), 78-109.

Bitter, G. The road to computer literacy: A scope and sequence model. Electronic Learning, 1982, 2(1), 60-65.

Carter, K. R., \& Ormrod, J. E. Acquisition of formal operations by intellectually gifted children. Gifted Child Quarterly, 1982, 26(3), 110-115.

Cattoche, R. A student guide for Apple II Plus. Seattle: Northwest Clearinghouse for Gifted Education.

Center for Learning Technologies. Computer literacy: An introduction. Albany, NY: State Education Department, 1982.

Clark, P., \& Williams, G. (Eds.). Game plan 1982. Byte, 1982, 7(12), 83-91.

Covvey, H. D., \& McAlister, H. H. Computer consciousness. Reading, MA: Addison-Wesley Publishing Co., 1980.

Edwards, J. A computer career for you? Best of Creative Computing, $1,37-42$.

Gibney, T. The gifted as problem-solvers in elementary schools. Roeper Review, 1982, 4(4), 13-14.

Goldenberg, E. P. LOGO - a cultural glossary. Byte, 1982, 7(8), 210-229.

Hampton, C. Introduction to computers. $G / C / T, 1980,12,44-45$.

Harvey, B. Why LOGO? Byte, 1982, 7(8), 195-196.

Hersberger, J., \& Wheatly, G. . A proposed model for a gifted elementary school mathematics program. Gifted Child Quarterly, 1980, 24(1), 37-40.

Johnston, J. Career opportunities in computing. Byte, 1982, 7(4), $439-446$.

Katz, E., \& Seeley, K. University of Denver's University for Youth. Journal for the Education of the Gifted, 1982, 5(3), 160-169.

Larsen, S. G. Computers for kids. Morristown, NJ: Creative Computing Press, 1981 .

Ludlow, B. L., \& Woodrum, D. T. Problem-solving strategies of gifted and average learners on a multiple discrimination task. Gifted Child Quarterly, 1982, 26(3), 99-103.

Malone, T. W. What makes computer games fun? Byte, 1981, 6(12), 258-277.

Melmed, A. S. Information technology for U.S. schools. Phi Delta Kappan, 1982, 63(5), 308-311.

Nansen, C. Teaching computer use - not programming. Electronic Learning, 1982, 2(3), 24-33.

Nay, F. Computer challenge: The Henry Taitt story, $G / C / T, 1981,20$, 48-50.

Osborne, A. Running wild: The next industrial revolution. Berkeley, CA: Osborne/McGraw-Hill, 1979.

Peterson, S. An overview of microcomputers in the school. Report to National Commission on Excellence, Department of Education, 1982.

Pritchard, W. H. Instructional computing in 2001: A scenario. Phi Delta Kappan, 1982, 63(5), 322-325.

Roberts, S. K. Artificial intelligence. Byte, 1981, 6(9), 164-179.

Rosenfield, S., \& Houtz, J. C. Developmental patterns in problem solving and divergent thinking abilities in gifted elementary school child ren. Journal for the Education of the Gifted, 1978, I (2), 37-48.

Seeley, K., Katz, E., \& Linder, T. The university as a community resource for the gifted: The University for Youth. Gifted Child Quarterly, 1981, 25(3), 112-115.

Skelton, J. E. An introduction to the BASIC language. New York: Holt, Rinehart \& Winston, 1971.

Solomon, C. Introducing LOGO to children. Byte, 1982, 7(8), 196-209.

Steele, K., Battista, \& Krockover, G. H. The effect of microcomputer assisted instruction upon the computer literacy of high ability students. Gifted Child Quarterly, 1982, 26(4), 162-164.

Sternberg, R. J. A componential theory of intellectual giftedness. Gifted Child Quarterly, 1981, 25(2), 86-93.
Sternberg, R. J. Teaching scientific thinking to gifted children. Roeper Review, 1982, 4(4), 4-6.

Torrance, E. P. Educating the gifted in the 1980's: Removing limits on learning. Journal for the Education of the Gifted, 1980, 4(1), 43-49.

Weinreb, W. Problem solving with LOGO. Byte, 1982, 7(11), 118-134.

Weinstein, J., \& Laufman, L. Teaching logical reasoning to gifted students. Gifted Child Quarterly, 1980, 24(4), 186-190.

Williams, G. A graphics primer. Byte, 1982, 7(11), 448-473.

Willis, J., Smithy, D., \& Hyndman, B. Peanut butter and jelly guide to computers. Portland, OR: Dilithium Press, 1978.

Withrow, F. B., \& Roberts, L. G. The video disc: Putting education on a silver platter. Electronic Learning, 1982, I(5), 43-45.

Yob, G. Pilot. Best of Creative Computing, 3, pp. 53-56.

\section{ADDITIONAL RESOURCES}

Minnesota Education Computing Consortium (MECC) 2520 Broadway Dr., St. Paul, MN 55113 $612 / 638-0600$

MECC is an organization created to coordinate and provide computer services to students, teachers, and educational administrators in Minnesota. At present, approximately 2,000 computer terminals and 2,500 microcomputers are located in schools and colleges across̀ the state.

A documentation center makes available written materials ranging from periodic newsletters to curriculum guides that offer assistance in implementing computer use in the classroom. The bimonthly newsletter, called Users, lists available diskettes that can be used with the Apple II, support booklets for these diskettes, and programming and reference manuals. (NonMinnesota customers must pay a surcharge to cover the MECC operating costs paid by MECC-member institutions). Both Users and Dataline, another bimonthly MECC newsletter, are free upon request.

\section{Northwest Regional Educational Laboratory Microcomputer Software and Information for Teachers (MicroSIFT) \\ 300 S.W. Sixth Ave., Portland, OR 97204 $503 / 248-6800$}

MicroSIFT, a project of Northwest Regional Educational Laboratory, serves as a clearinghouse for microcomputer K-12 instructional software information. The clearinghouse focuses both on establishing effective procedures for the collection, evaluation, and dissemination of materials and information, and on providing user support and technical assistance. Additional information is available through MicroSIFT Nen's, a quarterly newsletter. To be placed on the MicroSIFT New's mailing list, write to the above address. 